\title{
Effect of Process Parameters on Microporosity and Nanomechanical Properties of Aluminium Cenosphere Composite Foam Developed by Spray Forming Route
}

\author{
Amarish Kumar Shukla · J. Dutta Majumdar
}

Dept. of Metallurgical \& Materials Engineering, Indian Institute of Technology Kharagpur- 721302, India.

\begin{abstract}
The present work aims at understanding the effect of process parameters on the size and distribution of porosity and nanomechanical properties of aluminium cenosphere composite foam (CF) prepared by spray forming route. A detailed investigation of the microporosity and nano-mechanical properties of the foam have been undertaken through microcomputer tomography ( $\mu$-CT) and nanoindentation (NI) analysis, respectively. The $\mu$-CT results show that the spray formed composite foam introduces microporosity up to a maximum of $8.1 \%$, along with a few interconnected micropores. The localized mechanical properties of the CF have been measured in terms of nano hardness, elastic modulus, stiffness, and total energy absorption by nanoindentation analysis and compared with commercially pure (CP) aluminium. The sphericity results of the foam show that the pores are near spherical (with a sphericity index of 0.5 to 0.8 ), when the pore diameter is below $50 \mu \mathrm{m}$, beyond which, the sphericity index decreases $(0.175$ to 0.4$)$. The results of nanoindentation study show that the addition of cenosphere enhances the nanohardness from $538 \pm 24 \mathrm{MPa}$ (for CP aluminium) to $673 \pm 54 \mathrm{MPa}$ and energy absorption from $86 \pm 10 \mathrm{~nJ}$ (for CP aluminium) to $94 \pm 15 \mathrm{~nJ}$, however; it decreases the elastic modulus from $58 \pm 3$ (for CP aluminium) to $46 \pm 7 \mathrm{GPa}$.

(CIndian Thermal Spray Society, INScienceIN. 2021.All rights reserved
\end{abstract}

\section{Introduction}

In recent years, aluminium cenosphere composite foams are receiving more attention because of its low density, excellent energy absorption capacity, high specific strength, good sound absorption capacity, and electromagnetic interface shielding compared to their solid material counterparts [1-5]. Because of these excellent physical and mechanical properties, the foam has been used in numerous fields such as automotive, aerospace industries, railway, and structural applications for passenger safety $[2,6]$. In recent years, cenosphere gets attention in the large domain because of its huge availability, spherical nature, excellent thermal insulation and attractive cell wall mechanical and wear properties, which make it a suitable candidate for application as space holder to develop composite foam [7-9]. Several researchers have reported that the incorporation of cenosphere in the aluminium matrix effectively develops aluminium foam with reduced density, increased compressive strength and improved wear properties [9-13]. The overall mechanical properties can be evaluated by conventional mechanical testing. However, the role of the distributed cenosphere cell wall in aluminium matrix needs to be understood to get the overall behavior of the foam, in service which can only be identified by nanoindentation technique [14-16]. If the interface is not strong and defects free, it affects the overall mechanical properties such as plateau strength, tensile strength, and fatigue strength of foam [17-19]. In addition, the presence of micro-porosities also plays a role in determining the mechanical performance of the foam. Mukherjee et al. [18] fabricated aluminium foam by the powder metallurgy route and reported that microporosity adversely affects the cell wall properties of the foam. Though a few works of literature report the fabrication of aluminium foam by incorporation of cenosphere, however, limited information is available on the interfacial mechanical properties of cenosphere dispersed aluminium foam and a detailed study on the quantification of porosities. In the past, it is reported that the microporosities are generated during spray forming and it influences the properties of the foam [20-21]. However, the quantification of generated microporosity and their distribution throughout the matrix need to be investigated to know their effect on the local and average properties of the component. In addition, it is also reported that the interface boundary between aluminium matrix and cenosphere reinforcement, and the bonding between them influence the mechanical properties of the foam $[9,22]$. For understanding the bonding behavior between the matrix and reinforcement, the mechanical properties of the interface need to be investigated. In the present study, the advanced microcomputer tomography and Nano Indentation techniques have been utilized to quantify the size and distribution of the porosities and the mechanical properties at the interface between the cenosphere and matrix, respectively.

In the present work, aluminium cenosphere composite foam has been developed with 35 wt.\% of cenosphere by spray forming route under varied hydrogen pressure. Followed by the development of foam, a detailed study of the microstructures and micro-porosities of the foam has been undertaken. Finally, the mechanical property of the matrix and the interface between the cenosphere and aluminium has been studied by nanoindentation test to derive the Nano hardness (HIT), young's modulus (E), 
stiffness (S), elastic energy ( $\mathrm{W}_{\mathrm{E}}$ ), plastic energy (WP) and total energy absorption $\left(\mathrm{W}_{\mathrm{T}}\right)$ of the interface and has been compared with commercially pure (CP) aluminium.

\section{Experimental}

Commercially pure (CP) aluminium powder (Aldrich, -200 Mesh, 99\%), and cenosphere (Cenosphere India Ltd., Kolkata) of particle size in the range of $20 \mu \mathrm{m}-150 \mu \mathrm{m}$ has been utilized to prepare a foam by using spray forming technique. In this technique, a constant current of 400 Amp, argon gas pressure of 40 Psi and varying hydrogen pressure of 5 Psi and 10 Psihave been used to prepare the aluminium-cenosphere composite foam with the dimension of $10 \times 10 \times 5 \mathrm{~mm}^{3}$. The detailed experimental step followed in this study has been reported elsewhere [23]. The samples were sliced to 10-12 pieces and the cross sections of the spray formed coupons (thickness of $5 \mathrm{~mm}$ ) were subjected to all characterization as mentioned in the paper. The results shown are the average of 10-12 samples. The standard metallography technique has been used to prepare samples for microstructural investigation. The size and distribution of cenosphere, porosity, and the interface between the cenosphere and matrix have been examined by using a field emission gun scanning electron microscope (FESEM, Model: SUPRA 40, Make: Carl Zeiss, Germany). The overall density of the foam has been determined by water displacement technique using Archimedes principle. Microcomputer tomography $(\mu-\mathrm{CT})$ analysis has been conducted using a $\mu$ - CT scanning system (Model: Phoenix v|tome|xs, Make: GE, Germany) to identify the microporosity or voids in the foam sample, which is generated because of the spray forming route. The nanoindentation testing has been conducted by using nanoindentation test (Model: TriTec SA Nanoindenter, Make: Anton Paar, Switzerland) with a Berkovich tip made of industrial diamond with the tip radius of $0.1 \mu \mathrm{m}$, elastic modulus of $865 \mathrm{GPa}$ and Poisson's ratio (v) of 0.2. A maximum load of $100 \mathrm{mN}$, linear loading/unloading rate of $200 \mathrm{mN} / \mathrm{min}$ and dwell time of $10 \mathrm{~s}$ has been selected for a nanoindentation study of foam. Finally, the results are analyzed by using Indentation 7.3.10 software. For the nanoindentation study an average of 15 readings from three set of foam samples are selected to get the average mechanical properties and their reproducibility. An average reading has been considered to obtain the loaddisplacement ( $\mathrm{P}$ vs $\mathrm{h}$ ) curves of the foam samples. The hardness and young's modulus are calculated from the load-displacement graph using the Oliver and Pharr method [24]. The hardness, reduced modulus and young's modulus are derived from the nanoindentation test by using the following equation:

$$
\begin{aligned}
& H=\frac{P_{\max }}{A} \\
& \frac{1}{E_{r}}=\frac{1-\vartheta_{S}^{2}}{E_{S}}+\frac{1-\vartheta_{i}^{2}}{E_{i}}
\end{aligned}
$$

where $\mathrm{H}$ is the nanohardness in $\mathrm{MPa}, \mathrm{P}_{\max }$ is maximum applied load, A is projected area, $\mathrm{E}_{\mathrm{r}}$ is reduced modulus, $\mathrm{E}_{\mathrm{s}}$ is the modulus of the sample, $E_{i}$ is the modulus of the indenter, $v_{s}$ is the Poisson's ratio of the sample and $v_{i}$ is the Poisson's ratio of the indenter.

\section{Results and Discussion}

Characterization of Microstructure and Micro-defects

Figs.1(a-d) show the (a) scanning electron micrograph of cenosphere, (b) digitized optical micrograph of the top surface of spray formed aluminium-cenosphere composite, (c) scanning electron micrographs of the top surface of spray formed aluminium-cenosphere composite and (d) high magnification view showing the interface between cenosphere and matrix. Fig.1(a) shows that few cenosphere particles are fragmented due to its fragile nature. Few particles of cenosphere surface are smooth (marked with 1) and few of them are rough (marked with 2) surface. After the preparation of foam, the digital photomicrograph of foam samples has been obtained by a stereo zoom microscope (Leica: S8APO), which is shown in Fig. 1(b). Fig.1(b) shows the presence of microporosity (marked with circle and arrowhead) into the matrix which confirms that the porosity is generated into the matrix because of the presence of cenosphere as space holder as well as presence of porosity due to spray forming. Fig. 1(c) shows that the cenosphere particles are distributed uniformly throughout the matrix (marked with arrowhead). Furthermore, there is also the presence of cenosphere cluster (inside of a large circle), micropores (marked with a small circle) and broken particle of cenosphere into the matrix of foam. Fig. 1(d) shows that the cenosphere cavity is filled with broken particles of cenosphere and aluminium. In addition, cenosphere well adhered with the aluminium matrix, and the gap between matrix and cenosphere is $0.754 \pm 0.10 \mu \mathrm{m}$. The cell of cenosphere is of an approximate thickness of 4 $\mu \mathrm{m}$ and contains few micropores and micro-cracks.

The density of foams varies from $1.896 \pm 0.06 \mathrm{~g} / \mathrm{cm}^{3}$ to $1.917 \pm 0.11 \mathrm{~g} / \mathrm{cm}^{3}$ with variation in hydrogen pressure from 5 Psi (S1) to 10 Psi (S2), which is lower than the density of commercially pure aluminium $\left(2.7 \mathrm{~g} / \mathrm{cm}^{3}\right)$. The overall porosity of foam in terms of void percentage, pore size distribution and sphericity of pores, are determined using $\mu$-CT scanning technique. The volume percentage of porosity (voids) and the maximum volume of micropores are summarized in Table 1 . Table 1 shows that the volume percentage of voids in the foam S1 is relatively higher (8.1 vol.\%) than foam S2 (3.2 vol.\%). As the hydrogen pressure increases, the volume fraction of microporosity decreases. Due to the application of higher hydrogen pressure, a higher temperature is generated due to which the surface of cenosphere or small particle of cenosphere is partially/fully melted and is intermixed with the matrix. As hydrogen pressure increases, a few particles of cenosphere damages (Fig. 1 c.) and are mixed with metal matrix, causing a reduction in porosity of the foam. Fig.2 presents the 3D $\mu$-CT image of spray formed samples (a) S1 and (b) S2. A colour coding has been assigned in the images according to pore size and to obtain a visualization of pore distribution in the foam samples. Homogeneous distribution of pores is found in sample S1 with a maximum of 0.5 vol.\% porosity. On the other hand, in sample S2, the volume percentage of porosity varies from 0.5 vol.\% to 3.5 vol.\%. The void space is generated because of thermal misfit, cooling rate, and the gas introduced by spray forming [20]. The difference of microporosity in aluminium foam with process parameters reveals that the generation of microporosity has a dependence on the processing parameter. Distribution of equivalent pore 

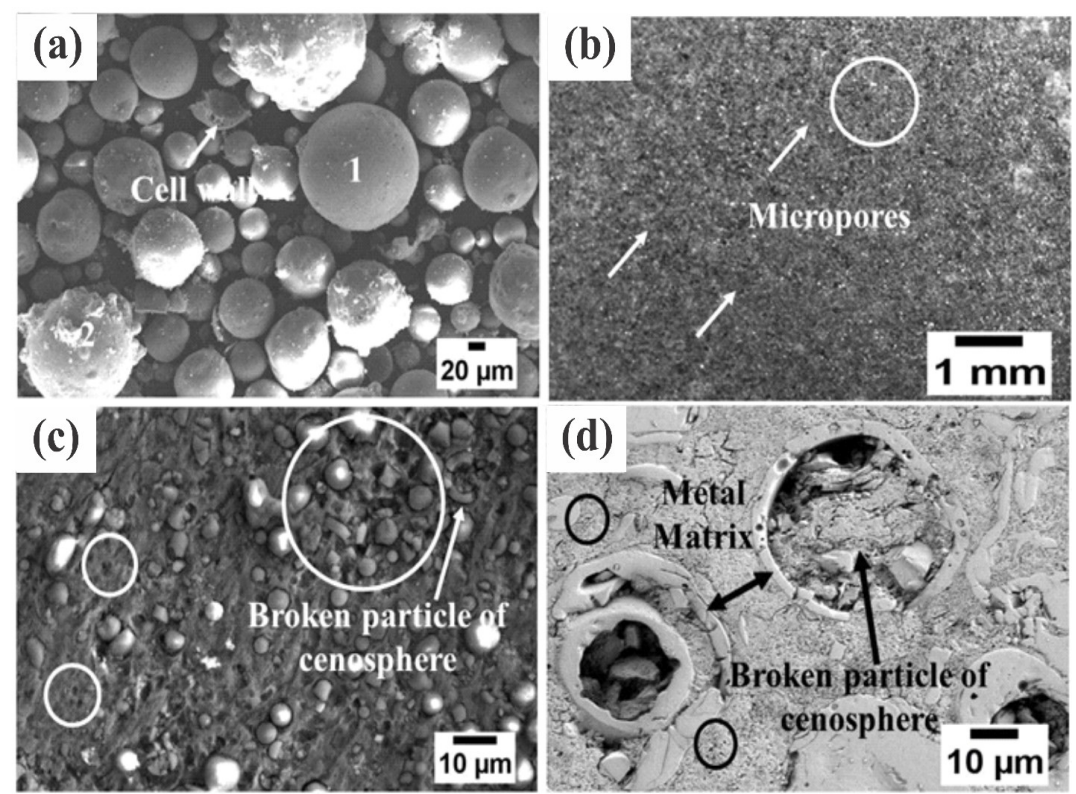

Figure 1: (a) Scanning electron micrograph of cenosphere, (b) micrograph of fabricated aluminium cenosphere composite foam,

(c) scanning electron micrographs of aluminium-cenosphere composite foam developed with 5 Psi hydrogen pressure and

(d) microstructure of interface between cenosphere and matrix

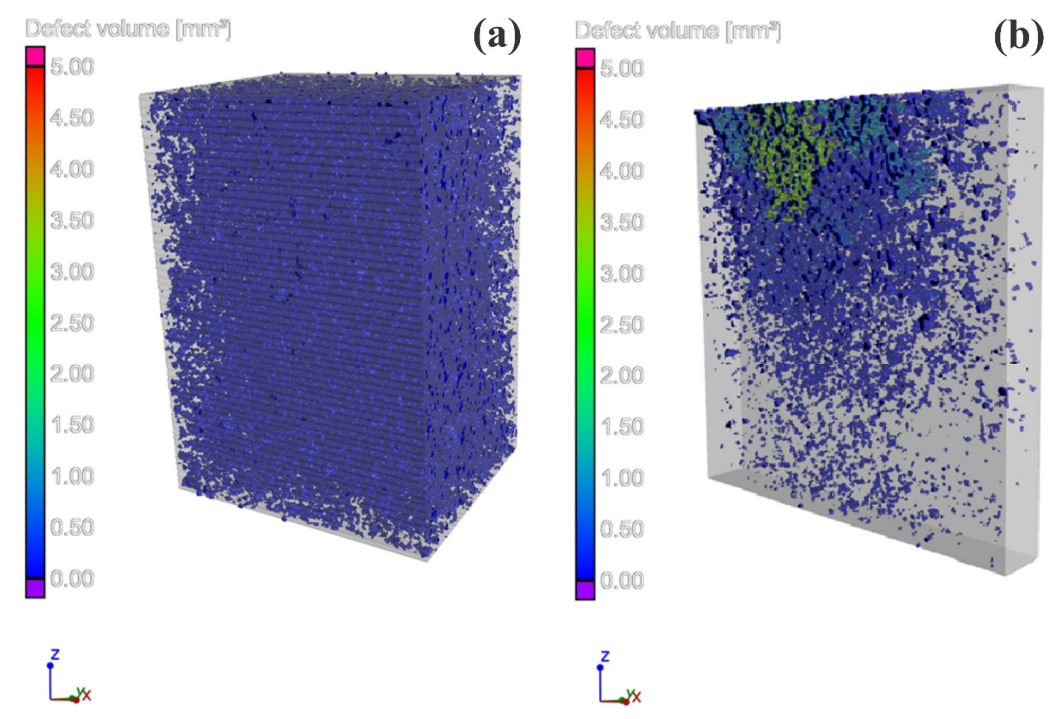

Figure 2: 3D $\mu$ - CT images of spray formed aluminium foam, processed with (a) 5 Psi (S1) and (b) 10 Psi (S2)

Table1: The processing parameters, density and physical properties of foam

\begin{tabular}{cccccccc}
\hline S.No. & $\begin{array}{c}\text { Sample } \\
\text { History }\end{array}$ & composition & $\begin{array}{c}\mathrm{H}_{2} \\
(\mathrm{Psi})\end{array}$ & $\begin{array}{c}\text { Density } \\
\left(\mathrm{g} / \mathrm{cm}^{3}\right)\end{array}$ & $\begin{array}{c}\text { Micro Hardness } \\
(\mathrm{HV})\end{array}$ & $\begin{array}{c}\text { Microporosity } \\
(\% \mathrm{og})\end{array}$ & $\begin{array}{c}\text { Maximum pore } \\
\text { volume }\left(\mathrm{mm}^{3}\right)\end{array}$ \\
\hline 1 & $\mathrm{~S} 1$ & Al+Cenosphere & 5 & $1.896 \pm 0.06$ & $35.16 \pm 4.11$ & 8.1 & 0.24 \\
2 & $\mathrm{~S} 2$ & Al+Cenosphere & 10 & $1.917 \pm 0.11$ & $37.8 \pm 3.81$ & 3.2 & 0.33 \\
\hline
\end{tabular}

diameter in the foam sample as a function of process parameters is shown in Fig. 3. From Fig. 3 it may be concluded that the pore size distribution in sample S1 lies within a very narrow range ( $50 \mu \mathrm{m}$ to $90 \mu \mathrm{m})$. On the other hand, the pore size distribution in sample S2 varies from 50 $\mu \mathrm{m}$ to $120 \mu \mathrm{m}$. At a low gas pressure, the degree of melting of cenosphere is less, as a result of which, porosities were mainly due to the presence of cenosphere in the matrix and hence, have the diameter corresponding to the diameter of cenosphere particles. The sphericity of foam is shown in Fig. 4. The sphericity of foam reveals that the nature of pores is near spherical for both the samples. On the other hand, pores with a larger diameter deviate from sphericity. The sphericity of pores is deviated with the larger pore diameter due to either the presence of few broken particles of the cenosphere or the formation of interconnected pores. As pore diameter or broken particles of cenosphere increases; it decreases the sphericity of foam. At 

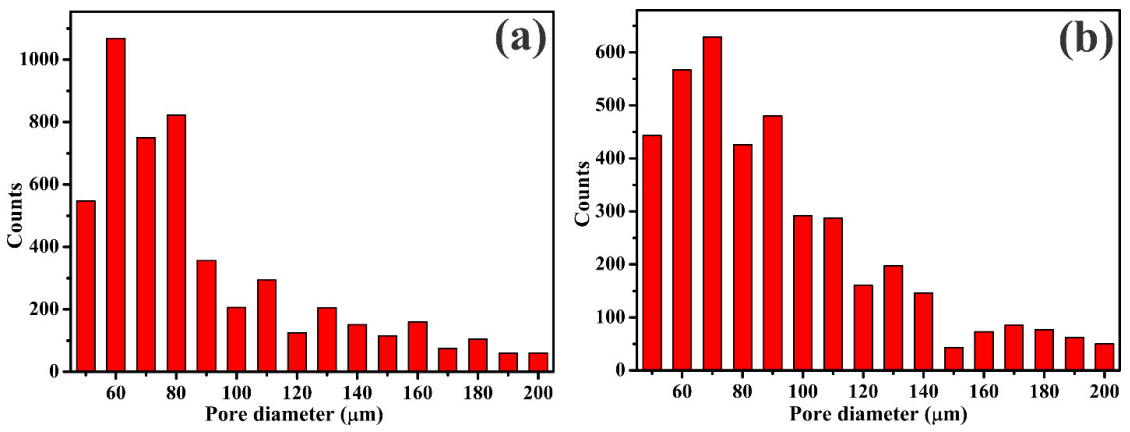

Figure 3: Distribution of equivalent pore diameter in the foam processed with (a) 5 Psi (S1) and (b) 10 Psi (S2)
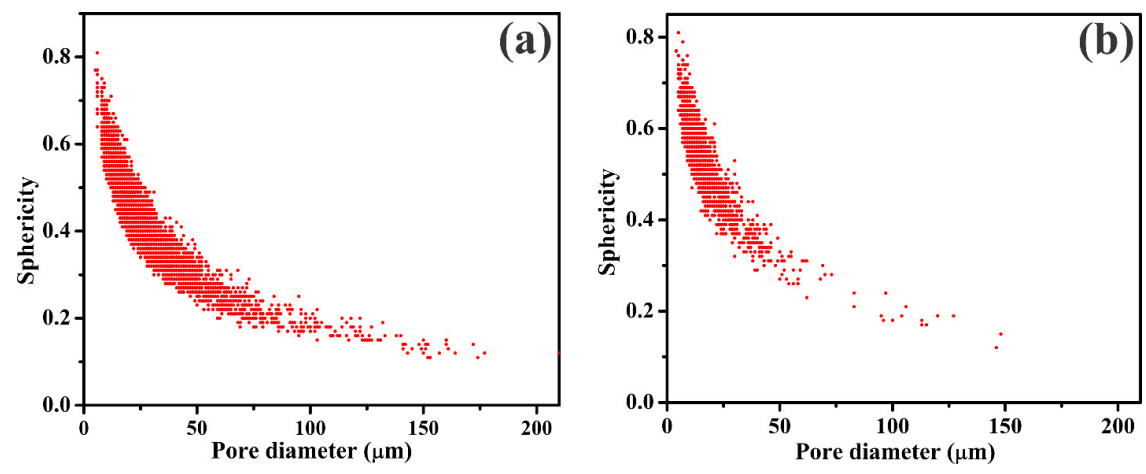

Figure 4: Sphericity of foam processed with (a) 5 Psi (S1) and (b) 10 Psi (S2)
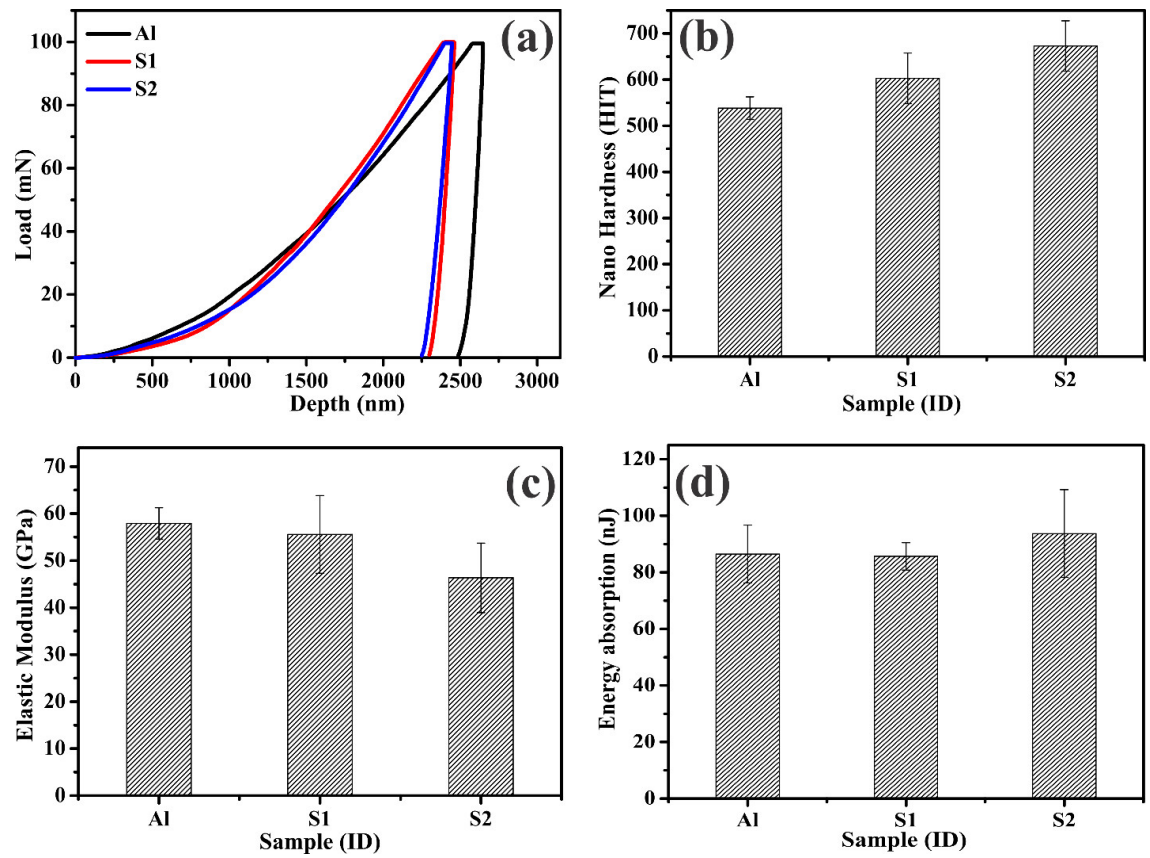

Figure 5: (a) Average load versus depth plot of commercial aluminium, aluminium cenosphere composite foam, and the bar chart showing the variation of (b) Nanohardness, (c) Young's modulus and (d) Energy absorption of aluminium foam processed with 5 Psi (S1) and 10 Psi (S2)

a higher hydrogen pressure $(10$ Psi $)$, particles of cenosphere break, leading to decrease in sphericity of the pores, as random pores/micro-cracks are generated due to gas entrapment, solidification shrinkage and loss of adherence at the interface between cenosphere and matrix. The above results show that total porosity and its sphericity index depend on the applied hydrogen pressure, which needed to be optimized. The findings will significantly impact designing the future foam with controlled porosity and their interconnectivity by spray forming route.

\section{Nano-mechanical properties}

Nanoindentation is a suitable technique to measure hardness and elastic modulus of foam on a micrometric range [14]. The mechanical properties of the interface 
Table 2: The mechanical properties of foam through nanoindentation route

\begin{tabular}{|c|c|c|c|c|c|c|c|}
\hline S.No. & $\begin{array}{l}\text { Sample } \\
\text { History }\end{array}$ & $\begin{array}{l}\text { Nano Hardness } \\
\qquad(\mathrm{MPa})\end{array}$ & $\begin{array}{l}\text { Elastic Modulus } \\
\text { (GPa) }\end{array}$ & $\begin{array}{l}\text { Stiffness } \\
(\mathrm{mN} / \mathrm{nm})\end{array}$ & $\begin{array}{c}\text { Elastic energy } \\
\text { (nJ) }\end{array}$ & $\begin{array}{c}\text { Plastic } \\
\text { Energy } \\
\text { (nJ) }\end{array}$ & $\begin{array}{c}\text { Energy } \\
\text { absorption } \\
(\mathrm{nJ})\end{array}$ \\
\hline 1 & $\mathrm{Al}$ & $538 \pm 24.34$ & $58 \pm 3.33$ & $1.10 \pm 0.21$ & $2.90 \pm 0.78$ & $83.58 \pm 10.20$ & $86.48 \pm 10.23$ \\
\hline 2 & S1 & $603 \pm 54.78$ & $56 \pm 8.27$ & $0.812 \pm 0.07$ & $6.62 \pm 0.78$ & $79.03 \pm 5.11$ & $85.65 \pm 4.82$ \\
\hline 3 & S2 & $673 \pm 54.51$ & $46 \pm 7.39$ & $0.828 \pm 0.10$ & $10.59 \pm 1.42$ & $83.10 \pm 13.53$ & $93.70 \pm 15.53$ \\
\hline
\end{tabular}
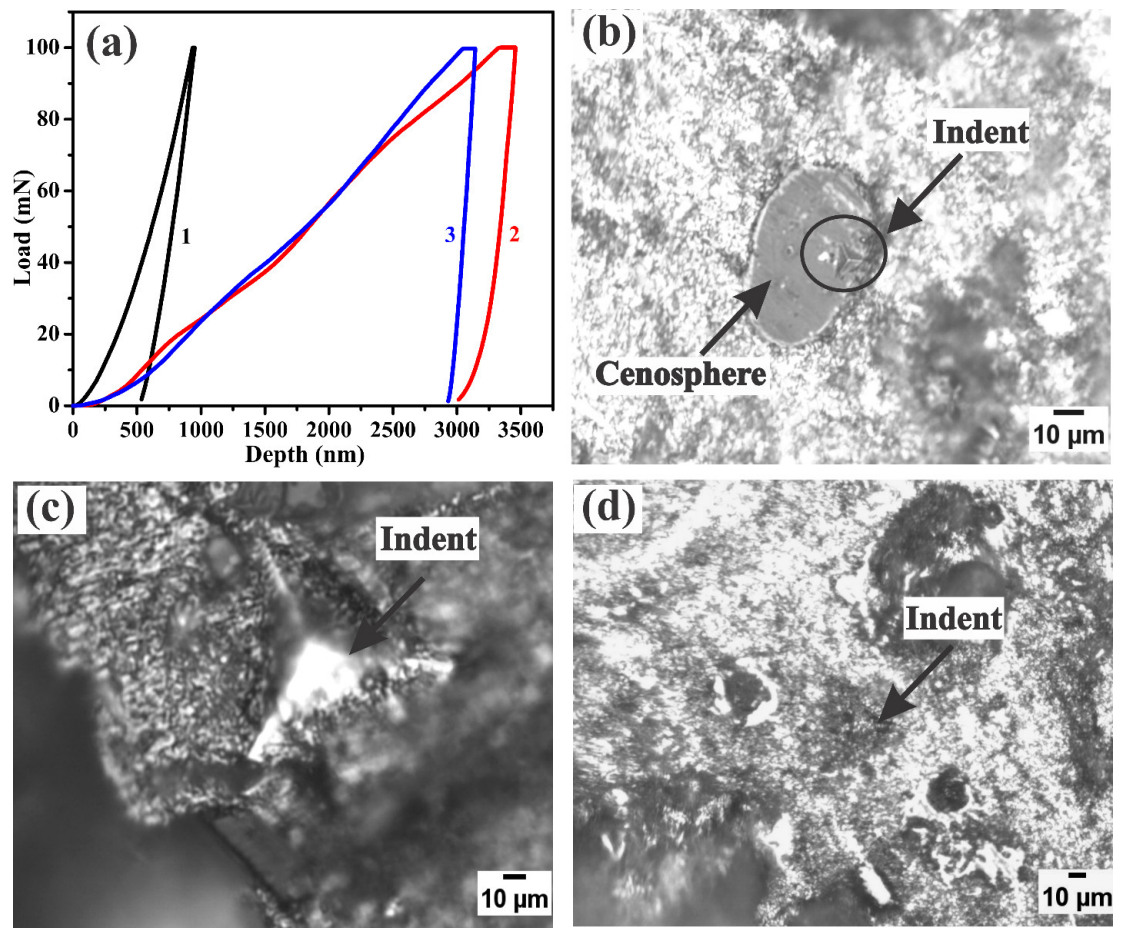

Figure 6: (a) Load versus depth curve, which shows the variation in mechanical properties, and optical micrograph of the Nanoindenter mark on (b) particle of the cenosphere

(c) interface between the matrix material and cenosphere, and the Indenter mark (d) in the matrix.

Table 3: Summary of nanoindentation parameters obtained from a nanoindentation study at different locations of the aluminium-cenosphere composite foam

\begin{tabular}{cccccccc}
\hline S.No. & $\begin{array}{c}\text { Sample } \\
\text { location }\end{array}$ & $\begin{array}{c}\text { Nano } \\
\text { Hardness } \\
(\mathrm{MPa})\end{array}$ & $\begin{array}{c}\text { Elastic } \\
\text { Modulus } \\
(\mathrm{GPa})\end{array}$ & $\begin{array}{c}\text { Stiffness } \\
(\mathrm{mN} / \mathrm{nm})\end{array}$ & $\begin{array}{c}\text { Elastic } \\
\text { energy } \\
(\mathrm{nJ})\end{array}$ & $\begin{array}{c}\text { Plastic } \\
\text { Energy } \\
(\mathrm{n}) \text { ) }\end{array}$ & $\begin{array}{c}\text { Energy } \\
\text { absorption } \\
(\mathrm{nJ})\end{array}$ \\
\hline 1 & Cenosphere & 6800 & 78 & 0.329 & 18.56 & 18.20 & 36.78 \\
2 & Interface & 240 & 34 & 0.771 & 8.36 & 91.02 & 99.36 \\
3 & Matrix & 588 & 58 & 0.897 & 6.98 & 85.27 & 92.25 \\
\hline
\end{tabular}

between the cenosphere and the matrix cannot be evaluated by conventional mechanical testing. The nanoindentation test has been chosen for nanomechanical characterization because it provides mechanical properties of the localized zone such as hardness, young's modulus, plastic energy and stiffness [14-15, 24]. Like conventional hardness, nanoindentation is measured based on the size of the residual impression created by diamond tip forced into the material. The actual average of load vs depth and their corresponding average mechanical properties in terms of hardness, young's modulus, and plastic energy are shown in Fig. 5 (a-d). Fig.5a shows the loading and unloading curve of as-received aluminium and aluminium-cenosphere composite foam processed under different hydrogen pressure. From Fig. 5 (b-d) it may be noted that the nanohardness of the aluminium-cenosphere composite foam is higher than the as-received aluminium. Also, the nanohardness of the spray formed sample processed at a higher hydrogen pressure (S2) is higher than the same at lower hydrogen pressure (S1). The increased nanohardness of the composite foam compared to the asreceived aluminium is attributed to the presence of a cenosphere hard shell in the aluminium matrix. The increased nanohardness of the sample processed at a higher hydrogen pressure is attributed to the higher density and less microporosity (3.2\% as compared to $8.1 \%$ for the same processed with 5 Psi) of aluminium cenosphere composite foam processed with 10 Psi. Elastic modulus decreases in cenosphere added aluminium composite foam, possibly due to porosities in the matrix 
and porous nature of the cenosphere cell wall. With an increase in hydrogen pressure, the elastic modulus decreases possibly due to the presence of an increased volume fraction of large diameter pores and the presence of micro-cracks at the interface between broken cenosphere particle and matrix. Energy absorbed on the samples did not change when spray forming was conducted at 5 Psi hydrogen pressure. On the other hand, energy absorption was significantly increased when processing was conducted at 10 Psi hydrogen pressure. Table 2 summarizes the parameters obtained from a nanoindentation study from the present set of samples. From Table 2 it may be observed that the nano hardness enhancement from $538 \mathrm{MPa}$ (for as-received aluminium) to $673 \mathrm{MPa}$ for cenosphere dispersed aluminium foam processed with 10 Psi hydrogen pressure. Elastic modulus decreases from $58 \mathrm{MPa}$ to $46 \mathrm{MPa}$ in cenosphere dispersed aluminium foam. Energy under elastic region found to increase due to dispersed cenosphere and the maximum elastic energy observed from the sample processed with 10 Psi hydrogen pressure. There is no significant change in plastic energy in aluminium foam as compared to asreceived aluminium. From the nanomechanical behavior, it may be stated that, though there is an increase in hardness and elastic modulus, there is not much change in the toughness of the aluminium foam. In the past, nanoindentation study of closed cell aluminium alloy foam subjected to different heat treated conditions has been reported by Mateja et al. [16].

To understand the effect of cenosphere addition of nanomechanical behavior of the aluminium foam, Nanoindentation was conducted at many locations of the foam containing no visible porosity at different locations. Fig. 6 a., shows the variation of depth of indentation with load $100 \mathrm{mN}$ at different locations of indentations, i.e., on cenosphere surface (plot 1), interface (plot 2) and in the matrix (plot 3), corresponding indentation marks are shown in fig. 6 (b-d). The nanoindentation parameters obtained from different locations of indentation are summarized in Table3. From Table 3, it may be noted that the hardness of cenosphere is very high $6800 \mathrm{MPa}$ because of the presence of hard mullite phase, it also having higher elastic modulus than that of the matrix. The elastic energy of cenosphere is higher than the matrix; however, the plastic energy of cenosphere is lower than that of the matrix and interface of aluminium and cenosphere. However, the mechanical properties of the interface show that it has the lowest hardness, elastic modulus, elastic energy, and plastic energy. The reduced hardness of the interface is attributed to probably the presence of microcracks between cenosphere and matrix. There is variation in nanoindentation in different locations of the foam sample is because of (a) presence of cenosphere throughout the matrix, (b) macropores generated because of broken particles of cenosphere, and (c) micropores generated because of processing route and (d) microdefects, in between matrix and pores, and in between matrix and cenosphere. Fig. 6 (b-d) shows the optical micrograph and the variation in indenter impression at different locations, i.e., on the cenosphere cell wall (cf. fig. 6 b), at the interface between cenosphere and matrix (cf. fig. 6 c), and on the matrix (cf. fig. $6 \mathrm{~d}$ ) of the foam. From Fig. $6 \mathrm{~b}$, it is revealed that when indent falls on the surface of the cenosphere, its size is minimum because of its maximum hardness. At the interface, the indent size is maximum, due to its lowest hardness value. The matrix shows the indentation size in between the same on cenosphere and interface.

\section{Conclusions}

In the present work, the effect of process parameters on the microstructure, size and distribution of porosity and localized mechanical properties of aluminium-cenosphere foam developed by spray forming route with 5 Psi and 10 Psi hydrogen pressure have been evaluated. From the detailed investigation, the following conclusions have been drawn:

1.Microstructures of the foam show the uniform distribution of cenosphere into the matrix with microporosity in the spray formed samples.

2.The $\mu$-CT study shows that the pore is of two different kinds: porosities due to hollow spherical cenosphere space holder and porosities due to materials evaporation or gas entrapment generated.

3. With an increase in hydrogen pressure from 5 Psi to 10 Psi, the volume percentage of microporosity decreases from 8.1 vol.\% to 3.2 vol.\%. The sphericity is close to 1 (0.5 to 0.8 ) when the particle size of pores was less than $50 \mu \mathrm{m}$; however, it decreased with an increase in the particle size of cenosphere.

4. The nanohardness increases from $538.28 \pm 24.34$ (for commercially pure $\mathrm{Al}$ ) to a maximum of $673 \pm 54.5$ (composite foam processed at 10 psi hydrogen pressure) $\mathrm{MPa}$ and the modulus decreases from $57.921 \pm 3.33$ (for Al) to $46.34 \pm 7.39 \mathrm{GPa}$ (composite foam processed at 10 psi hydrogen pressure), which confirms that the addition of cenosphere increases the hardness and decreases the young's modulus of foam; however, the energy absorption of foam is significantly increased compared to commercial aluminium.

5.The nanoindentation analysis reveals that the mechanical properties of foam depending on the pore morphology, and distribution of cenosphere particles throughout the matrix.

6.The mechanical property of the interface shows that cenosphere particle possess a maximum nanohardness and due to the presence of microcracks, the interface shows lowest nanohardness and the nanohardness of the matrix is in between of cenosphere and the interface hardness.

7.It is also concluded that the nanoindentation properties depends on the distribution of cenosphere reinforcement, microporosity, and the presence of micro defects between the matrix and cenosphere interface.

\section{Acknowledgement}

The partial financial support for the present study from Aeronautic Research and Development Board (ARDB), N. Delhi is gratefully acknowledged. The characterization facility extended by the Central Research Facility, IIT Kharagpur is too gratefully acknowledged.

\section{References}

1. Nazirudeen, S. S. M., A Development of Technology for Making Porous Metal Foams Castings, Jordan J. Mech. Ind. Eng., 2010, 4(2), 292-299. 
2. Banhart, J., Metal Foams: Production and Stability, Advanced Engineering Materials. 2006, 8(9), 781-794.

3. Garcia-avila, M., Portanova, and M., Rabiei, A. Ballistic Performance of Composite Metal Foams. Compos. Struct., 2015, 125, 202-211.

4. Singh, A. K., Shishkin, A., Koppel, T., and Gupta, N, A Review of Porous Light weight Composite Materials for Electromagnetic Interference Shielding, Compos. Part B Eng., 2018,149,188-197.

5. Duarte, I., and Oliveira, M, Aluminium Alloy Foams: Production and Properties. Powder Metall., 2012, 47-72.

6. Ashby, M. F., Evans, A. G., Fleck, N. A., Gibson, L. J., Hutchinson, J. W., and Wadley, H. N. G, Metal Foams: A Design Guide, Butterworth-Heinemann: Elsevier, 2000,1 $1^{\text {st }}$ ed.

7. Vishwakarma, A., Mondal, D. P., Birla, S., Das, S., and Prasanth, P, Effect of Cenosphere Size on the Dry Sliding Wear Behaviour LM13-Cenosphere Syntactic Foam, Tribol. Int., 2017, 110, pp.8-22.

8. Ranjbar, N., and Kuenzel, C., Cenospheres: A Review, Fuel, 2017, 207,1-12.

9. Mondal, D. P., Das, S., Ramakrishnan, N., and Uday Bhasker, K., Cenosphere Filled Aluminum Syntactic Foam Made through Stir-Casting Technique. Compos. Part A Appl. Sci. Manuf., 2009, 40(3), 279-288.

10. Jha, N., Badkul, A., Mondal, D. P., Das, S., and Singh, M., Sliding Wear Behaviour of Aluminum Syntactic Foam: A Comparison with $\mathrm{Al} 10 \mathrm{Wt} \% \mathrm{SiC}$ Composites, Tribol. Int., 2011, 44(3), 220-231.

11. Jha, N.,Mondal,D. P, Goel,M. D.,Majumdar, J. D.,Das, S., and Modi, O. P., Titanium Cenosphere Syntactic Foam with Coarser Cenosphere Fabricated by Powder Metallurgy at Lower Compaction Load, Trans. Nonferrous Met. Soc. China, 2014, 24(1), 89-99.

12. Shukla, A. K., and Majumdar, J. D., Studies on Microstructure and Mechanical , Properties of Aluminium Foam Prepared by Spray Forming Route, Procedia Manufacturing, 2019, 35, 861-865.

13. Majumdar, D. D., Ghosh, M., Mondal, D. P., and Roy choudhury, A., Fretting Wear Resistance of Titanium Foam Developed by Powder Metallurgy Route. Procedia Manuf., 2019,35, 833-839.

14. Hasan, M. A., Kim, A., and Lee,H. J., Measuring the Cell Wall Mechanical Properties of Al-Alloy Foams Using the Nanoindentation Method, Compos. Struct. 2008 , 83(2), 180188.

15. Králík,V., Comparison of Nanoindentation Techniques for Local Mechanical Quantification of Aluminium Alloy, Materials Science \& Engineering A, 2014, 618, 118-128.

16. Šnajdar Musa, M., Marić, G., and Grilec, K., Nanoindentation of Closed Cell Al Alloy Foams Subjected to Different Heat Treatment Regimes. Compos. Part B Eng., 2016, 89, 383387.

17. Lee, C. Do., Effects of Microporosity on Tensile Properties of A356 Aluminum Alloy. Mater. Sci. Eng. A, 2007, 464(1-2), 249-254.

18. Mukherjee M., García-Moreno F., Jiménez C., Rack A., Banhart J., Microporosity in Aluminium Foams, Acta Mater., 2017, 131, 156-168.

19. Vogiatzis, C. A., A., Tsouknidas, D., Kountouras ,T., Skolianos S., Aluminum-ceramic cenospheres syntactic foams produced by powder metallurgy route, Mater. Des., 2015,85, 444-454.

20. Singer, A. R. E. Metal Matrix Composites Made by Spray Forming. Mater. Sci. Eng. A, 1991, 135, 13-17.

21. Reddy BVR, Maity SR, and Pandey KM. Characterization of spray formed Al-alloys - A Review. Rev Adv Mater Sci 2019, 58, 147-58.

22. Vogiatzis CA, and Skolianos SM, On the sintering mechanisms and microstructure of aluminium-ceramic cenospheres syntactic foams produced by powder metallurgy route. Composite Part A Appl. Sci. Manuf., 2016, $82,8-19$.
23. Shukla, A. K., and Majumdar, J.D., Studies on Wear Behavior of Aluminium Foam Developed by Spray Forming Route, Mater.Today Proc., 2019, 19, 532-535.

24. Oliver, W. C., and Pharr, G. M., An Improved Technique for Determining Hardness and Elastic Modulus Using Load and Displacement Sensing Indentation Experiments. J. Mater. Res., 1992, 7(6) 1564-1583. 